\title{
Extended training: Delay of reward
}

\author{
GARVIN MCCAIN, ANNAMARIE BOODEÉ, and MICHAEL LOBB \\ University of Texas, Arlington, Texas 76019
}

\begin{abstract}
Rats run in a straight alley were given either 10- or 30-sec prereinforcement delay in the goalbox. Subgroups were later shifted. There was no PCE or NCE. Early in training the 10-sec group ran fastest; late in training this difference disappeared.
\end{abstract}

For several years research on the effects of extended training and repeated shifts has been a principal focus of this laboratory. A wide range of reinforcement parameters, such as magnitude of consistent reinforcement, percentage of reinforcement, magnitude of partial reinforcement, and delay of reinforcement, have given substantial differences early in training. Late in training these differences have disappeared. These studies are cited in more detail elsewhere (McCain, Lobb, Almand, \& Leck, 1976). The present study was designed to replicate and extend the earlier delay study (McCain et al., 1976) since it was a single study.

\section{METHOD}

\section{Subjects}

The subjects were 29 male rats of the Holtzman strain. All subjects were approximately 110 days old at the beginning of the experiment. Two rats became sick during the study and were discarded. Their scores are not included in the data.

\footnotetext{
Apparatus

The plywood straight alley was $160 \mathrm{~cm}$ long. Run time was measured over a $45-\mathrm{cm}$ section beginning at the startbox door. Goal time was measured over a $30.5-\mathrm{cm}$ section, beginning with the photoelectric cell which terminated the run time and ending with a cell approximately $2 \mathrm{~cm}$ inside the goal box door.

\section{Procedure}

The subjects were allowed 2 weeks for adjustment to the laboratory before being placed on deprivation. Subjects were maintained throughout the experiment on a 13-g schedule. Food received in the alley was deducted from cage feeding. The subjects were placed on deprivation on Day 1 and handled 2 min daily. On Days 7 through 10 the subjects explored the unbaited maze for $3 \mathrm{~min}$ daily. During this period the equipment was turned on and doors were raised and lowered. Subjects were randomly assigned to groups for the acquisition phase. One half were given acquisition with a 10-sec delay of reinforcement (S). The other half received a 30-sec delay of reinforcement (L). All subjects were given 43 acquisition trials. Three trials were given the first day, four the second, and five trials daily thereafter. At the end of acquisition, the groups were matched internally and divided into four groups: LLLL, LSLS, SSSS, SLSL. Delay conditions during the shifts were designated in the same way as in acquisition. There were 20 trials during each of the three shifts. All subjects were given 15 extinction trials following Shift 3. Each group was matched internally; half were extinguished using a 10-sec goalbox confinement, the other half were given 30 -sec goalbox confinement. The reinforcement on each acquisition or shift trial was eight 45 -mg Noyes pellets.
}

\section{RESULTS AND DISCUSSION}

Daily median times were transformed to a speed measure $[\log 10(1 / \mathrm{med}+1)]$. The transformed goal and run speeds give compatible results. Only the goal speed data will be presented. Figure 1 shows the last 80 trials for the control groups, LLLL and SSSS. The group effect was not significant $(\mathrm{F}=3.66, \mathrm{df}=1 / 12$, $\mathrm{p}<.10>.05)$. The interaction of Groups by Blocks was significant $(F=4.67, d f=3 / 26, p<.025)$. Analysis by individual blocks shows a significant difference in Block $1(\mathrm{~F}=9.65, \mathrm{df}=1 / 12, \mathrm{p}<.01)$. None of the

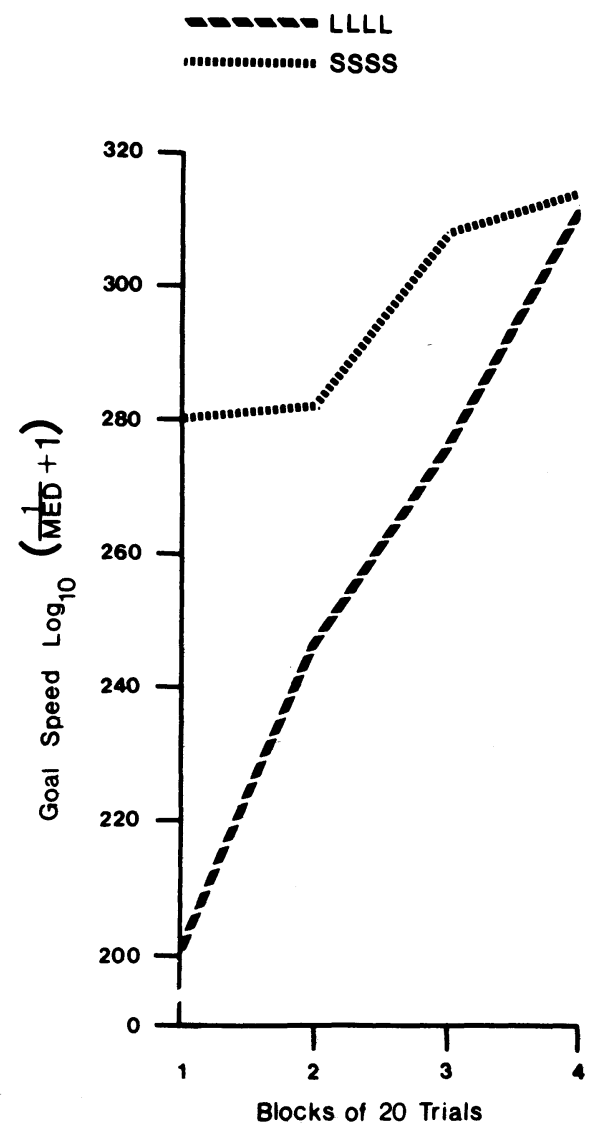

Figure 1. Goal speeds for the 10- and 30-sec control groups over the last 80 trials. 
other blocks differences was significant. During the fourth block the groups are within a rounding error of one another, giving a very small $F$ ratio $(F=.0002)$. There were no significant PCEs or NCEs, although the direction of the differences is compatible with those reported earlier (McCain et al., 1976). There were no significant extinction effects but, again, the results are compatible with the earlier study.

The results of this study support the earlier finding that different periods of delay lead to faster speeds early in training by the short-delay group, but late in training these differences disappear. The implications of such a finding have been discussed elsewhere (McCain et al., 1976; McCain, Lobb, \& Newberry, in press).

\section{REFERENCES}

McCain, G., Lobb, M., Almand, W., \& Leck, D. Delay of reinforcement: Extended training and multiple shifts. Bulletin of the Psychonomic Society, 1976, 7, 539-541.

McCaIn, G., LobB, M., \& NewBerRY, J. Extended training and multiple shifts: Percentage of reward. Bulletin of the Psychonomic Society, 1976, 8, 191-193.

(Received for publication September 15, 1976.) 